\section{A "Green" Extraction Protocol to Recover Red Pigments from Hot Capsicum Fruit}

\author{
Richard D. Richins, Laura Hernandez, Barry Dungan, Shane Hambly, \\ F. Omar Holguin, and Mary A. O'Connell' \\ Department of Plant and Environmental Sciences, New Mexico State \\ University, MSC 3Q, P.O. Box 30003, Las Cruces, NM 88003
}

Additional index words. capsaicinoids, capsanthin, carotenoids, pepper, pungency, supercritical fluid extraction

\begin{abstract}
Plant pigments represent a source of non-toxic compounds that are used as food or cosmetic coloring agents. Red-fruited varieties of Capsicum annuum can be extracted to isolate the red-colored xanthophylls, capsanthin, and capsorubin. Common commercial processes for this extraction use hexane as the extracting solvent and mild or no heat varieties of Capsicum. In this report, we describe a process for efficient extraction of these red pigments using green chemistry: $\mathrm{CO}_{2}$ supercritical fluid extraction and trapping the pigments in ethanol. Furthermore, we demonstrate that this method can be performed on hot or pungent Capsicum fruit and the resulting pigment sample has very low levels of capsaicinoids, 1 to $2 \mathrm{ppm}$. This process then can reduce the use of hazardous solvents and expand the type of fruit that can be used for the extraction of red pigments.
\end{abstract}

The red-, orange-, and yellow-pigmented fruit in Capsicum spp. is the result of accumulation of carotenoids, both carotenes and xanthophylls, in the pericarp (Wall et al., 2001). These pigments have beneficial nutritional value as precursors for vitamin $\mathrm{A}$ and as antioxidants (Clevidence et al., 2000; Fraser and Bramley, 2004; Simonne et al., 1997). In addition to their nutritional value, the red pigments in particular are important as sources of non-toxic red dyes (Sun, 1985). These red pigments are added to many processed foods and to some cosmetics to enhance their appearance (Wall and Bosland, 1998). The xanthophylls extracted from Capsicum fruit have become an important economical source of red pigments that can replace carcinogenic synthetic red dyes.

Typically, dried red fruit are extracted as a mash in a large heated volume of hexane; the extracted liquid is recovered and the hexane is evaporated or distilled from the sample leaving an oleoresin. Capsaicinoids, the compounds that are responsible for the heat or pungency of the Capsicum fruit, are also readily soluble in hexane. So to produce an oleoresin with no pungency, only mild or nonpungent red-pigmented fruit can be extracted.

Received for publication 17 Mar. 2010. Accepted for publication 16 May 2010.

This work was supported in part by the NM Agricultural Experiment Station, USDA CSREES grant 2008-34604-19434, and National Institutes of Health grants NIGMS GM61222 and S06 GM08136.

We are grateful to V. Hernandez at Rezolex Corp., Radium Springs, NM, for the gift of the Capsicum oleoresin sample and to Dr. P.W. Bosland, NMSU for Capsicum fruit and seed.

${ }^{1}$ To whom reprint requests should be addressed; e-mailmoconnel@nmsu.edu.
Breeding programs to develop varieties of Capsicum for higher yields of red pigmentation need to also breed in a non-pungent or mild Capsicum background (HorneroMéndez et al., 2002; Walker et al., 2004). In New Mexico, the economic value of a chile (C. annuum, L.) crop includes the value of the fruit harvested as a fresh green product and a dried red product often harvested at a later time in the season. Using current extraction processes, red pigment can only be recovered from American paprika varieties or other mild cultivars. If the extraction of the red pigments could be achieved separate from the capsaicinoids, then a wider range of red-fruited cultivars could be used, including ones with important values also as a fresh green crop.

Disposal of hazardous waste generated by industrial processes is expensive and becoming unpopular because water sources are accidentally contaminated with improper disposal. If alternative and environmentally sound, socalled "green" extraction protocols could be developed to replace the use of hexane as a solvent for oleoresin production, this would improve the environmental risks for the isolation of red pigments from Capsicum fruit. Supercritical fluid extractions (SFE) using $\mathrm{CO}_{2}$ as the solvent is one such green extraction method that is especially suited for the extraction of non-polar analytes (King and Hopper, 1992). Methods for the extraction of capsaicinoids by SFE have been described (Peusch et al., 1997; Sato et al., 1999). Several groups have described SFE methods for the extraction of pigments from Capsicum. In some cases, the authors have used paprika types of Capsicum, which are non-pungent, so interference of capsaicinoids coextracting with the pigments was avoided (Ambrogi et al., 2002; JarenGalan et al., 1999). In a few cases (Gnayfeed, et al., 2001; Perva-Uzunalic et al., 2004;
Uquicke et al., 2004), pungent Capsicum samples were used in the extraction of pigments; however, in those cases, extraction conditions were designed for the recovery of both the pigments and the capsaicinoids. Paprika oleoresins, typically prepared by hexane extraction, are generated for their pigment concentrations. They also need to have reduced capsaicinoid levels, no more than $0.5 \%$ or less than $25 \mathrm{ppm}$. These oleoresins are generated by extracting paprika types of chile fruit, those with less than 700 Scoville heat units capsaicinoids (Walker et al., 2004). To date, no SFE methods have been reported that allow for the preferential extraction of carotenoid pigments from pungent Capsicum fruit.

In this report, we describe a green chemical method that generates an oleoresin from dried Capsicum fruit with virtually the same carotene and xanthophyll composition as a hexane extraction method. Furthermore, this method includes a step that separates the pigments from the capsaicinoids. This last feature increases the flexibility of the process to allow a variety of red Capsicum fruit, pungent and non-pungent, to be used easily for pigment production.

\section{Materials and Methods}

Plant material. Mature red fruit of Capsicum annuum cvs. NuMex Garnet, Sandia, Barkers Hot, and Long Red Cayenne were collected from field-grown plants at New Mexico State University Fabian Garcia Science Center, Las Cruces, NM. Entire fruit were dried for 48 to $72 \mathrm{~h}$ at $47{ }^{\circ} \mathrm{C}$ in a forced-air oven and then the fruit were ground to a powder using a Retsch GrindoMix (GM200, Haan, Germany). Dried ground cayenne powder was purchased at local retail sources. Oleoresin was obtained from Rezolex Corp. (Las Cruces, NM). Leaf material from 'NuMex Garnet' was collected from greenhouse-grown material, dried, and powdered as described for fruit.

Chemicals. Purified standards for capsanthin and capsorubin were obtained from CaroteNature (Lupsingen, Switzerland); $\beta$-carotene, capsaicin, and dihydrocapsaicin were obtained from Sigma-Aldrich (St. Louis, MO). All other chemicals were high-pressure liquid chromatography or American Chemical Society reagent grade.

Extractions. SFE was performed using an ISCO SFX 3560 Super Critical Fluid Extractor with a Neslab RTE-101 recirculating water chiller. The final optimal conditions were up to $3 \mathrm{~g}$ dried, ground fruit was placed in the thimble and extracted with $20 \%$ ethanol $(95 \%)$ as a modifier for $5 \mathrm{~min}$ static, $20 \mathrm{~min}$ dynamic at $60{ }^{\circ} \mathrm{C}, 4800 \mathrm{psi} \mathrm{CO}_{2}(0.86 \mathrm{~g} / \mathrm{mL})$; we removed the modifier and re-extracted, $5 \mathrm{~min}$ static, $20 \mathrm{~min}$ dynamic at $60^{\circ} \mathrm{C}, 4800 \mathrm{psi}$ $\mathrm{CO}_{2}$; and finally, the restrictor was washed with $5 \mathrm{~mL}$ ethanol. This resulted in $\approx 7 \mathrm{~mL}$ of an ethanol extract in the collection tube for each thimble extracted. The ethanol is considered a modifier, because it was present during the first extraction cycle with the supercritical $\mathrm{CO}_{2}$. The restrictor is the metal tube that dispenses the extract from the pressurized thimble. This tube was washed with ethanol to 
rinse out all of the extract. The restrictor was washed between samples, and blank extraction thimbles were placed between each sample thimble to prevent any carryover between samples. The sample was then adjusted to $76 \%$ ethanol by the addition of $1.4 \mathrm{~mL}$ water. The samples were placed on ice for $\approx 30 \mathrm{~min}$ and then centrifuged $0{ }^{\circ} \mathrm{C}, 4000 \mathrm{rpm}$, for $20 \mathrm{~min}$. The supernate and the pellet were collected separately. For characterization, the pellet was resuspended in hexane, typically $5 \mathrm{~mL}$.

Two different hexane extractions were performed. The first was an overnight batch extraction with hexane, $1 \mathrm{~g}$ dried commercial cayenne powder with $70 \mathrm{~mL}$ hexane for $16 \mathrm{~h}$ at room temperature. The hexane was decanted and the oleoresin dried under a stream of nitrogen. The weight of the carotenoids extracted by the hexane was determined. The second hexane extraction was performed using a Dionex ASE 350. In this case, $3 \mathrm{~g}$ of dried ground red Capsicum fruit from the varieties listed in "Plant Materials" was placed in a $5-\mathrm{mL}$ steel thimble and extracted with hexane with the following settings: $8 \mathrm{~min}$ static, $40^{\circ} \mathrm{C}$, $1500 \mathrm{psi}$; hexane-extracted samples were dried under $\mathrm{N}_{2}$ gas to reduce the final volume to $5 \mathrm{~mL}$. The term ASE hexane extraction is used in the article to distinguish this extraction process from the batch extractions.

In cases in which the samples were saponified, the method described by HorneroMéndez et al. (2002) was used with the following modifications: $300 \mu \mathrm{L}$ of carotenoids in hexane were mixed with $300 \mu \mathrm{L}$ methanolic $\mathrm{KOH}$ for $1 \mathrm{~h}$ at $50{ }^{\circ} \mathrm{C}$ with frequent vortexing; and the free carotenoids were separated from the acyl groups with the addition of $300 \mu \mathrm{L} \mathrm{H}_{2} \mathrm{O}+300 \mu \mathrm{L} \mathrm{CHCl}_{3}$. The mixture was vortexed and then centrifuged to resolve the phases. The non-aqueous phase was collected and spotted on thin-layer chromatography (TLC) plates for analysis.

Chromatography and analyses. Capsaicinoid content of the extracts was determined on a Waters Acuity Ultra Performance Liquid Chromatography (UPLC) with a BEH C18 $1.7 \mu \mathrm{m}$ $2.1 \times 50$-mm column based on methods described by Collins et al. (1995). The capsaicinoids were resolved using an acetonitrile-water gradient from $20 \%$ to $100 \%$ acetonitrile, flow rate of $0.5 \mathrm{~mL} / \mathrm{min}$, and detected by fluorescent emission at $338 \mathrm{~nm}$ after excitation at $280 \mathrm{~nm}$. Capsaicin eluted at $1.80 \mathrm{~min}$ and dihydrocapsaicin eluted at $1.95 \mathrm{~min}$. The linear response range for the calibration curve for both capsaicin and dihydrocapsaicin was 0 to $250 \mathrm{ppm}$.

TLC to characterize the carotenoids was performed on silica (60 F 254) aluminum sheets (Merck, Darmstadt, Germany) developed with butanol 5\% (v/v), hexane 76\% $(\mathrm{v} / \mathrm{v})$, ethyl acetate $9.5 \%(\mathrm{v} / \mathrm{v})$, and dichloromethane $9.5 \%(\mathrm{v} / \mathrm{v})$.

American Spice Trade Association (ASTA) measurements were performed as described by Wall and Bosland (1998).

\section{Results and Discussion}

A series of experiments were conducted using ground, dried cayenne powder avail- able in the local supermarkets to establish the conditions for pigment recovery using an SFE approach. Because oleoresin production for pigment preparation uses hexane as the solvent, the temperature and pressure of the $\mathrm{CO}_{2}$ solvent was set to generate a density of $0.86 \mathrm{~g} / \mathrm{mL}$ to correspond to the Hildebrand Solubility Parameter of hexane, 7.24. In these preliminary analyses, different combinations of pressure and temperature, each generating the desired density, were investigated: $40^{\circ} \mathrm{C}$, 3100 psi; $50{ }^{\circ} \mathrm{C}, 4000 \mathrm{psi}$; and $60{ }^{\circ} \mathrm{C}, 4800$ psi. Visual inspection of the remaining residue indicated that maximal extraction of the pigments occurred at $60{ }^{\circ} \mathrm{C}, 4800 \mathrm{psi}$. TLC analysis of the pigments extracted by the SFE demonstrated that the composition was the same as the pigments present in the oleoresin (Fig. 1). The yield or recovery of pigments, however, was reduced in the SFE extract to $\approx 31 \%$ of that seen with a hexane extract. A hexane extraction of the same dried cayenne powder $(1 \mathrm{~g})$ recovered $0.08 \mathrm{~g}$ pigment in 70 $\mathrm{mL}$ hexane after $16 \mathrm{~h}$ extraction compared with $0.025 \mathrm{~g}$ pigment in $10 \mathrm{~mL}$ ethanol after 35 min SFE extraction.

The addition of ethanol as a modifier in the SFE protocol was investigated as well as an additional SFE extraction cycle to increase the yield of pigments recovered. Visual inspection of the residue left after SFE treatment was routinely used to determine if improvements were achieved. Figure 2 demonstrates the effect of incorporation of ethanol as a modifier and the efficiency of extraction on varying amounts of dried chile powder. The upper panel (Fig. 2A) shows the residue left after SFE extraction of 1 to $5 \mathrm{~g}$ of powder with a single cycle of extraction at $60{ }^{\circ} \mathrm{C}, 4800$ psi. The lower panel (Fig. 2B) shows the residue left after the same SFE extraction with ethanol added as a comodifier. Comparison of the color of the original powder with the various residues clearly demonstrates that the addition of ethanol to the SFE protocol increased red pigment extraction. Furthermore, the extraction system could tolerate up to $3 \mathrm{~g}$ powder without apparent loss of pigment extraction efficiency. Finally, a stepwise extraction cycle increased the efficiency of extraction of the carotenoids; the final optimal method included two SFE extraction cycles at $60{ }^{\circ} \mathrm{C}, 4800 \mathrm{psi}$ each for $25 \mathrm{~min}$; the first cycle included ethanol as a modifier.

The pigments extracted by these SFE conditions tended to precipitate in the ethanol solvent used to collect them, shortly after the SFE run. To increase this process, the extracts were chilled to $0{ }^{\circ} \mathrm{C}$ for at least $1 \mathrm{~h}$ and often $24 \mathrm{~h}$. After extraction and before the chilling step, the ethanol was diluted with water from $95 \%$ to $76 \%$. This increase in water content also increased the precipitation extent of the carotenoids without altering the solubility of the capsaicinoids in the ethanol supernate. The samples were then centrifuged to recover the pigments in the pellet.

To confirm that this SFE method would reliably extract carotenoid pigments from dried chile samples, four different chile vari- eties were tested: three pungent lines ('Barkers Hot', 'Long Red Cayenne', and 'Sandia') and one non-pungent line ('NuMex Garnet'). The carotenoid pigments extracted using the optimized SFE method were compared with those extracted in an ASE hexane extract using TLC (Fig. 3). As expected, the composition and relative abundance of pigments in these two types of extracts from all four samples were very similar. These results suggest the SFE method extracts all of the visible pigments from Capsicum fruit in about the same amounts as an ASE hexane extraction.

The majority of red pigments extracted by either the ASE hexane method or the SFE method from the four different cultivars did not comigrate with either the capsanthin or capsorubin standards. To determine if this difference in mobility was the result of acylation of the pigments with fatty acids, the SFE sample from Capsicum, cultivar Barker's Hot, was saponified and then characterized by TLC (Fig. 4). The red pigments in the saponified sample now had a relative mobility similar to capsanthin, indicating that most of the red xanthophylls in dried chile fruit was accumulated as acylated derivatives.

A quantitative assessment of the pigments recovered by the SFE method was performed using the ASTA method. The ASTA units in the SFE pellet, the SFE supernatant, and the ASE hexane extracts of four different Capsicum cultivars were determined and are reported in Table 1. A comparison of the ASTA units in the SFE pellet and the ASE hexane extract for each cultivar provided an indication of the relative efficiency of the SFE process for pigment extraction. For example, in 'Sandia', the SFE pellet had $97 \%$ of the ASTA values extracted by hexane, whereas for 'Long Red Cayenne', the SFE pellet had $83 \%$ of the ASTA values extracted by hexane.

The capsaicinoids in the SFE pellet, the SFE supernate, and the ASE hexane extract were also determined by UPLC and are listed in Table 1. As expected, no capsaicinoids were detected in the non-pungent cultivar NuMex Garnet. Virtually all of the capsaicinoids extracted by the SFE method remained in the ethanol supernate; only 1 to $2 \mathrm{ppm}$ was detected in the pigment-rich SFE pellet fraction. In comparison, the ASE hexane pigmented fraction had 25 to 55 ppm capsaicinoids, well above the permitted level for red pigment use.

The use of the SFE method to extract carotenoids from other plant material was tested using carrots [Daucus carota L. subsp. sativus (Hoffm.) Arcang.] and corn (Zea mays, L. subsp. mays). For these plant materials, the SFE method did extract carotenoids; however, they did not form a pellet in the ethanol as the chile carotenoids did. Saponified carotenoids from chile also did not form a pellet in the ethanol. From these observations, we hypothesized that the high degree of acylation of the carotenoids in chile fruit make them less soluble in the ethanol resulting in good physical separation as a pellet. This method to extract and then concentrate 
the carotenoids using SFE and ethanol will work well with plant material rich in xanthophylls that are acylated, as is the case with

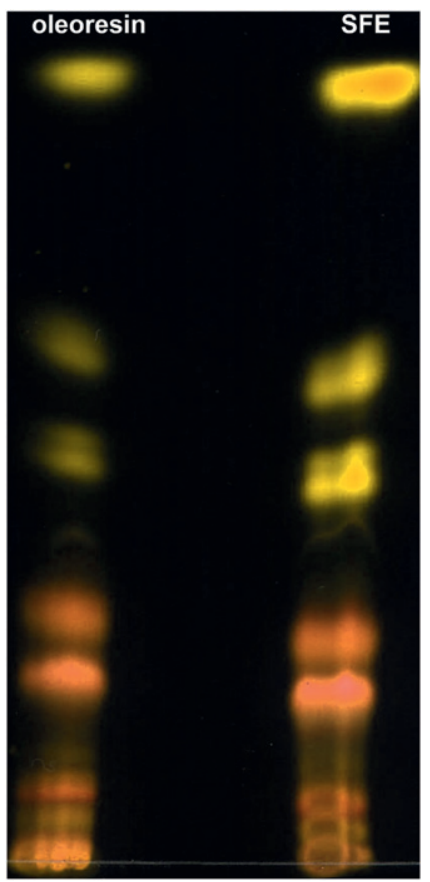

Fig. 1. Composition of carotenoids in commercial oleoresin and SFE extract of dried ground cayenne powder. Samples were spotted on silica thin-layer chromatography (TLC) plates and developed with butanol 5\% (v/v), hexane $76 \%(\mathrm{v} / \mathrm{v})$, ethyl acetate $9.5 \%(\mathrm{v} / \mathrm{v})$, and dichloromethane $9.5 \%(\mathrm{v} / \mathrm{v})$. A false black background image of the TLC plate was generated with Photoshop so the yellow carotenoids could be more readily identified.

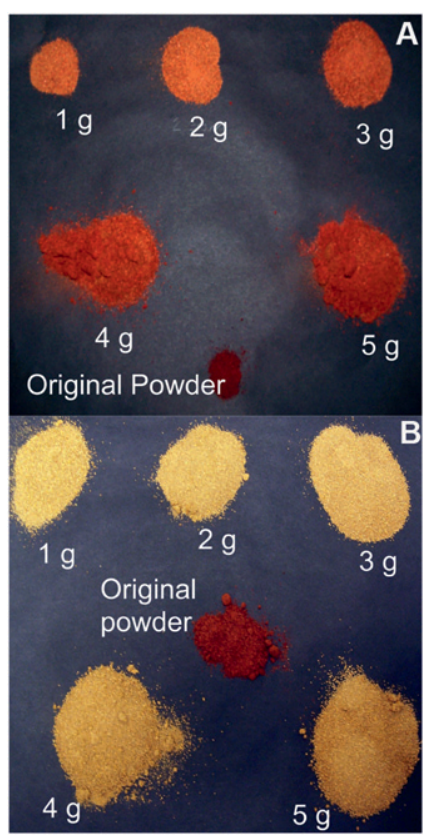

Fig. 2. Residues after supercritical fluid extraction (SFE) compared with original powder. Dried ground cayenne powder $(1,2,3,4$, or $5 \mathrm{~g})$ were extracted by SFE (A) or by SFE with ethanol as a modifier (B)

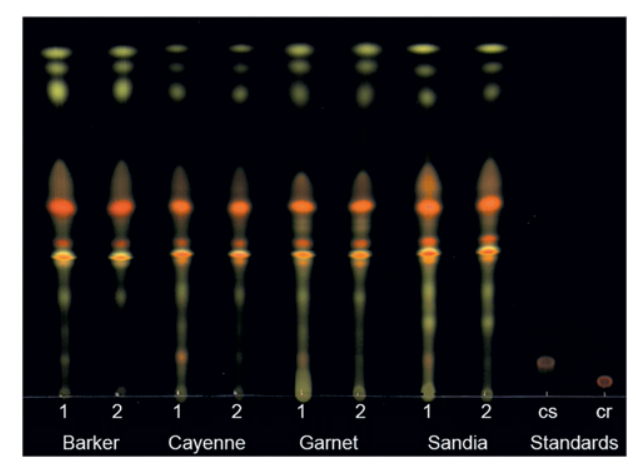

Fig. 3. Composition of carotenoids in ASE hexane extracts and supercritical fluid extraction (SFE) extracts from Capsicum varieties. Thin-layer chromatography system as in Figure 1. Lanes are labeled to indicate hexane extraction (1) or SFE (2) and the cultivar name; $\mathrm{cs}=$ capsanthin or $\mathrm{cr}=$ capsorubin standards.

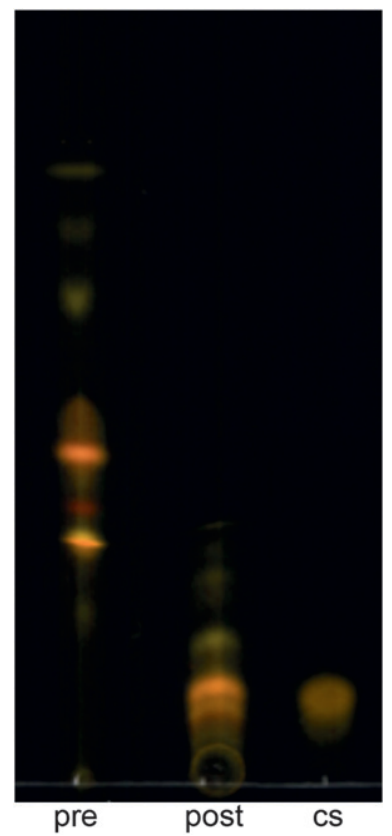

Fig. 4. Characterization of saponified carotenoids by thin-layer chromatography (TLC). Supercritical fluid extraction (SFE) extracts were saponified and spotted on silica TLC plates. The samples were labeled pre and post to indicate before and after saponification. cs $=$ capsanthin. TLC system as in Figure 1. chile pericarp (Hornero-Méndez and Mínguez-Mosquera, 2000).

The dried chile powder made from the four different Capsicum varieties was made from fruit collected by research scientists. There were no leaves of stems in these samples. Commercial harvests of the fruit may be contaminated with leaves and stems, even when harvested by hand in the field. The quality of the pigment in the oleoresin can be reduced if chlorophyll from dried green plant organs is present in the dried fruit material. The SFE method for pigment extraction provides an advantage over a hexane extraction. The pigments extracted from dried cayenne powder mixed with dried Capsicum leaf powder at different ratios were resolved by TLC and are shown in Figure 5. The pigments extracted by the ASE hexane method from cayenne powder samples mixed with $10 \%$ or $25 \%$ dried leaf powder by weight had noticeable contamination with chlorophyll. In contrast, very little chlorophyll contamination was detected in the pigments extracted by SFE from the fruit-leaf mixtures (Fig. 5).

\section{Conclusions}

A "green chemical" method has been developed that recovers $85 \%$ or greater of the pigmented carotenoids from dried Capsicum

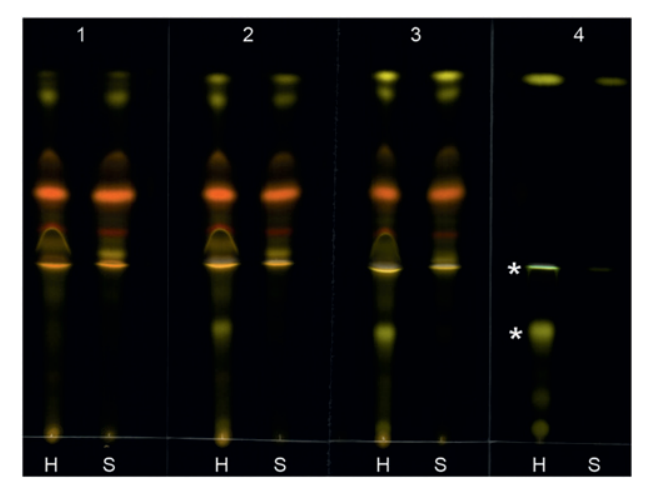

Fig. 5. Carotenoids from cayenne powder and leaf mixtures using ASE hexane $(\mathrm{H})$ or supercritical fluid extraction (SFE) (S) for extration. (1) Dried ground cayenne powder, $1 \mathrm{~g}$; (2) dried ground cayenne powder $(0.9 \mathrm{~g})$ with dried ground chile leaf powder $(0.1 \mathrm{~g}) ;(3)$ dried ground cayenne powder $(0.75 \mathrm{~g})$ with dried ground leaf $(0.25 \mathrm{~g}) ;(4)$ dried ground leaf powder $(1 \mathrm{~g})$. Thin-layer chromatography system as in Figure 1. Prominent chlorophyll bands are marked with an asterisk in 4. 
Table 1. Comparison of red pigment abundance as ASTA values and capsaicinoid abundance in ppm using the supercritical fluid extraction (SFE) method versus the ASE hexane method in several different Capsicum lines.

\begin{tabular}{lccc}
\hline Capsicum source & SFE pellet & SFE supernate & ASE hexane \\
\hline ASTA values & & & \\
NuMex Garnet & $161 \pm 2.0$ & $44 \pm 2.3$ & $176 \pm 2.0$ \\
Barkers Hot & $158 \pm 1.5$ & $29 \pm 2.3$ & $176 \pm 5.5$ \\
Long Red Cayenne & $137 \pm 8.9$ & $54 \pm 1.1$ & $165 \pm 1.9$ \\
Sandia & $175 \pm 2.0$ & $46 \pm 1.6$ & $180 \pm 4.6$ \\
Capsaicinoids (ppm) & & & 0 \\
NuMex Garnet & 0 & $56.9 \pm 5.0$ & $28.4 \pm 6.4$ \\
Barkers Hot & $0.8 \pm 0.0$ & $95.9 \pm 2.4$ & $54.5 \pm 21.4$ \\
Long Red Cayenne & $1.5 \pm 0.1$ & $57.8 \pm 1.7$ & $25.7 \pm 4.6$ \\
Sandia & $1.2 \pm 0.2$ & & \\
\hline
\end{tabular}

${ }^{\mathrm{z}}$ Average $\pm \mathrm{sD}, \mathrm{n}=3$ American Spice Trade Association (ASTA) color values.

yTotal capsaicinoids, capsaicin + dihydrocapsaicin.

fruit. This method works well with a variety of Capsicum fruit types, including highly pungent lines. The addition of a precipitation step to recover the pigments allows for the differential isolation of pigments separate from the capsaicinoids. Furthermore, the SFE method does not extract significant amounts of chlorophyll pigments that may be present as contaminants in a dried fruit sample. The SFE solvent, $\mathrm{CO}_{2}$, and the comodifier and trapping solvent, ethanol, are both non-hazardous materials. Use of this green chemical approach will reduce the hazardous waste associated with isolation of pigments from Capsicum. The differential precipitation step allows the pigment industry and Capsicum farmers to use virtually any variety of chile regardless of heat level for pigment production. Pungent chiles with high ASTA values could be grown for either food/ spice uses or pigment production. In the future, growers may rely on mechanical harvest of chiles; this technology is currently under development. Contamination of the red fruit with stems and leaves may become higher than in a hand harvest. This SFE extraction method provides an advantage for red fruit harvests mixed with leaf material because it reduces the amount of chlorophyll that contaminates the carotenoid pigment extracts as compared with a hexane extract.

\section{Literature Cited}

Ambrogi, A., D.A. Cardarelli, and R. Eggers. 2002. Fractional extraction of paprika using supercritical carbon dioxide and on-line determination of carotenoids. J. Food Sci. 67:3236-3241.

Clevidence, B., I. Pateau, and J.C. Smith. 2000. Bioavailability of carotenoids from vegetables. HortScience 35:585-588.

Collins, M.D., L. Mayer-Wasmund, and P.W. Bosland. 1995. Improved method for quantifying capsaicinoids in Capsicum using high performance liquid chromatography. HortScience 30:137-139.

Fraser, P.D. and P.M. Bramley. 2004. The biosynthesis and nutritional uses of carotenoids. Prog. Lipid Res. 43:228-265.

Gnayfeed, M.H., H.G. Daood, V. Illes, and P.A. Biacs. 2001. Supercritical $\mathrm{CO}_{2}$ and subcritical propane extraction of pungent paprika and quantification of carotenoids, tocopherols and capsaicinoids. J. Agr. Food Chem. 49:2761-2766.

Hornero-Méndez, D., J. Costa-García, and M.I. Mínguez-Mosquera. 2002. Characterization of carotenoid high-producing Capsicum annuиm cultivars selected for paprika production. J. Agr. Food Chem. 50:5711-5716.

Hornero-Méndez, D. and M.I. Mínguez-Mosquera. 2000. Xanthophyll esterification accompanying carotenoid overaccumulation in chromoplast of Capsicum annuum ripening fruits is a constitutive process and useful ripeness index. J. Agr. Food Chem. 48:1617-1622.
Jaren-Galan, M., U. Nienaber, and S.J. Schwartz. 1999. Paprika (Capsicum annuum) oleoresin extraction with supercritical carbon dioxide. J. Agr. Food Chem. 47:3558-3564.

King, J.W. and M.L. Hopper. 1992. Analytical supercritical fluid extraction: Current trends and future vistas. J. Assoc. Off. Anal. Chem. Intl. 75:375-378.

Perva-Uzunalic, A., M. Skerget, B. Weinreich, and Z. Knez. 2004. Extraction of chilli pepper (var. Byedige) with supercritical $\mathrm{CO}_{2}$ : Effect of pressure and temperature on capsaicinoid and colour extraction efficiency. Food Chem. 87: 51-58.

Peusch, M., E. Muller-Seitz, M. Petz, A. Muller, and E. Anklam. 1997. Extraction of capsaicinoids from chillies (Capsicum frutescens L.) and paprika (Capsicum annuum L.) using supercritical fluids and organic solvents. Z. Lebensmittel. Forsch. A 204:351-355.

Sato, K., S.S. Sasaki, Y. Goda, T. Yamada, O. Nunomura, K. Ishikawa, and T. Maitani. 1999. Direct connection of supercritical fluid extraction and supercritical fluid chromatography as a rapid quantitative method for capsaicinoids in placentas of Capsicum. J. Agr. Food Chem. 47:4665-4668.

Simonne, A.H., E.H. Simonne, R.R. Eitenmiller, H.A. Mills, and N.R. Green. 1997. Ascorbic acid and provitamin A contents in unusually colored bell peppers (Capsicum annuи L.). J. Food Comp. Anal. 10:299-311.

Sun, M. 1985. Food dyes fuel debate over Delaney; FDA commissioner Frank Young suggests that relative risk should play a role in banning cancer-causing additives. Science 229:739.

Uquicke, E., J.M. del Valle, and J. Ortiz. 2004. Supercritical carbon dioxide extraction of red pepper (Capsicum annuum L.) oleoresin. J. Food Eng. 65:55-66.

Walker, S., M.M. Wall, and P.W. Bosland. 2004. 'NuMex Garnet' paprika. HortScience 39:629630.

Wall, M.M. and P.W. Bosland. 1998. Analytical methods for color and pungency of chiles (capsicums), p. 347-373. In: Wetzel, D. and G. Charalambous (eds.). Instrumental methods in food and beverage analysis. Elsevier Science, Amsterdam.

Wall, M.M., C.A. Waddell, and P.W. Bosland. 2001. Variation in $\beta$-carotene and total carotenoid content in fruits of Capsicum. HortScience 36:746-749. 